\title{
EDITORIAL
}

\section{Infection and remodelling: a 21st century model of bronchiectasis?}

\author{
C. Ward*, K. Rydell-Törmänen" ${ }^{\#}$, G. Westergren-Thorsson`, L.T. Eriksson ${ }^{\star}$ and H. Walters ${ }^{+}$
}

$\mathbf{N}$ on-cystic fibrosis bronchiectasis is defined according to morphological criteria as the permanent dilatation of bronchi. Numerous causes have been identified, with a common end-point of repeated, vicious cycles of infection, inflammation and airway structural changes [1]. There is a general belief that the incidence of bronchiectasis is falling, but this is poorly researched [1,2]. When assessed, prevalence estimates vary widely between populations from 3.7 per 100,000 children in New Zealand to 52 per 100,000 adults in the USA [1].

Clinical descriptions of bronchiectasis made over 200 yrs ago by René Théophile Hyacinthe Laennec, the inventor of the stethoscope, vividly reflect the considerable associated morbidity: "This affection of the bronchia is always produced by chronic catarrh, or by some other disease attended by long, violent, and often repeated fits of coughing" [3].

The spectrum of bronchiectasis can range from mild, almost asymptomatic disease, through to disease showing accelerated loss of lung function and leading to death. Such decline of lung function in bronchiectasis is often associated with chronic colonisation by Pseudomonas aeruginosa, the occurrence of severe exacerbations, and evidence of systemic inflammation [1].

The British Thoracic Society clinical guidelines on bronchiectasis have recently been published [2]. A notable aspect of the guidelines was that much of the evidence cited had the designation of "level D" i.e. non-analytic studies (e.g. case reports, case series) or expert opinion.

In this issue of the European Respiratory Journal (ERJ), MARTIN et al. [4] provide much-needed thorough research of potential relevance to human bronchiectasis. Using epithelial cell lines, primary human epithelia and a murine model, they investigated the effects of Pseudomonas challenge, importantly assessing the effect of both lab- and patient-derived pathogens. The study showed that infection with $P$. aeruginosa induced vascular endothelial growth factor (VEGF) synthesis in airway epithelium and led to peribronchial angiogenesis in mice. Use of epidermal growth factor receptor (EGFR) blockers indicated that these observations were due in part to EGFR-dependent

\footnotetext{
*Transplant and Immunology Group, Institute of Cellular Medicine, University of Newcastle, Newcastle upon Tyne, UK. " Dept of Clinical Science, Section for Rheumatology, Lund University. 'Dept of Experimental Medical Science, Unit of Lung Biology, Lund University, Lund, Sweden. ${ }^{+}$NHMRC National Centre of Research Excellence in Chronic Respiratory Disease, Menzies Research Institute, University of Tasmania, Hobart, Australia.

CORRESPONDENCE: C. Ward, Institute of Cellular Medicine, University of Newcastle, Newcastle upon Tyne, NE2 4HH, UK. E-mail: chris.ward@ncl.ac.uk
}

mechanisms. Noting the finding of haemoptysis in human bronchiectasis, MARTIN et al. [4] suggest that EGFR inhibitors may have a role in reducing airway angiogenesis in chronic airway diseases, characterised by infection. The authors also noted that such findings need further examination in humans.

It is well recognised clinically that the airways in bronchiectasis are hyperaemic in appearance, and bleed easily. There are ample radiological and macro-anatomic data to back this up $[5,6]$ and it has been well demonstrated that airway infection can stimulate angiogenesis in animal models [7]. However, there has been little research on the details of angiogenesis or abnormally dilated vessels in the diseased bronchiectatic airway in humans, nor on the cellular or mediator aetiology of such changes. More is known about airway vessel changes in asthma, post-lungtransplant bronchiolitis obliterans syndrome (BOS) and chronic obstructive pulmonary disease (COPD). Some of the same principles may apply to the airway in bronchiectasis, and the interrelationships between bronchiectasis, asthma, COPD and other airway diseases have been detailed $[2,8]$.

We know most about asthma, which has received the most study. In this immuno-inflammatory airway remodelling pathophysiology, there is well-established hypervascularity and angiogenesis in the subepithelial lamina propria. These vessels are leaky [9], and the combination of resulting oedema, plus the volume of the vessels themselves in this physiologically strategic compartment just inside the muscle layer, may contribute to the pathophysiology of asthma especially during acute attacks. Hypervascularity on the lamina propria has been related to airflow obstruction [10], but especially to airway hyperresponsiveness [11]. A key driving growth factor is likely to be VEGF [12], with also a resetting of the VEGF receptor system towards an activated endothelium [13].

In post-lung-transplant BOS, angiogenesis in the airways occurs early and may not be progressive [14], although it may affect lung function [15]. Unlike in asthma, this process seems not to be driven by VEGF; indeed, VEGF underproduction may be part of the pathology [12]. Furthermore, this is a neutrophilic process and it may be the neutrophil chemokines, or their anti-microbial peptide products $[16,17]$, that drive the angiogenic process. It is noteworthy that neutrophilic variants of asthma are being described [18], which means that further work is required to understand what the implications of this condition are for vessel changes.

COPD is in every way a complex disease, and in spite of its major impacts socially and personally throughout the world, 
is relatively little studied, perhaps especially in terms of the details of its airway pathology. The lung parenchymal component of COPD may well be due to downregulation of VEGF production [19]. The changes in the airway wall are especially complex and data on angiogenesis in this compartment have until recently been somewhat confusing and conflicting [20-22], with changes perhaps more related to smoking than COPD itself [12]. VEGF has been implicated in the airway component of COPD [23].

Recent work has indicated that there is partitioning of contrasting vascular pathology in the airway wall: hypovascularity with older larger vessels in the deeper lamina propria; and hypervascularity with smaller new vessels in association with the subepithelial reticular basement membrane [24]. There is increased VEGF expression in association with the reticular basement membrane vessel changes, and this is related to fixed airflow obstruction. This indicates the potential complex nature of angiogenic changes in airway pathophysiologies for which animal models, such as that used by MARTIN et al. [4], may be helpful.

When investigating the vascular structures of the lung, using mice to model disease, it is however of utmost importance to recognise the differences between mice and humans. An important example is differences in circulation. In humans, two sets of circulatory systems (the bronchial and pulmonary systems) supply the lung [25]. The bronchial circulation, originating in the aorta and thus part of the systemic circulation, does not normally participate in gas exchange, which in contrast constitutes the main function of the pulmonary circulation [25]. Importantly and in contrast to humans, mice do not have a bronchial circulation originating from the systemic circulation: the pulmonary circulation supplies the entire lung. Interestingly in humans, this is also the case after lung transplantation.

In mice, inflammatory responses due to allergen exposure, lipopolysaccharide or infection are known to induce vascular remodelling of the pulmonary circulation, described in pulmonary arteries, veins and parenchymal microvessels [26] in addition to peribronchial microvessels [4]. The vascular remodelling observed includes increased smooth muscle, increased collagen synthesis and increased proliferation, although it predominantly affects smaller vessels. In contrast, the parenchymal microvessels are found to display a more muscularised phenotype [27, 28].

Persistent inflammation is a cardinal feature of bronchiectasis [1] and there are potential interactions with the circulation. Interestingly, studies investigating pulmonary vascular physiology in mice following allergic airway inflammation suggest that inflammation results in a hyperreactive response to hypoxia [29] and production of vasoactive mediators such as endothelin (ET)-1 and serotonin [30].

In microvascular endothelial cells, hypoxia has been shown to induce secretion of VEGF and ET-1 [31] through the expression of hypoxia-inducible factor (HIF)-1, which in turn is known to evoke recruitment of circulating monocytes and/or mononuclear fibrocytes. HIF-1 consists of two subunits, HIF- $1 \alpha$ and HIF-1 $\beta$, which, during hypoxic conditions, form a transcription factor that regulates expression of about 100 genes, with some involved in anaerobic metabolism and others in angiogenesis and apoptosis [32]. Hypoxia also increases the expression of the chemokine
(CXC motif) ligand 12 (CXCL12) in endothelial cells, epithelial cells and cells subjected to injury-induced stress. In addition to CXCL12, expression of its receptor CXCR4 is also increased, particularly on fibrocytes [33]. Binding of CXCL12 to fibrocytes results in the release of VEGF, matrix metalloproteinase (MMP)-9 and nitric oxide, as well as cytoskeletal rearrangement that allows increased mobility and chemotaxis [34]. Interestingly, increased numbers of tissue fibrocytes have been related to pathological remodelling of lung parenchyma and pulmonary vessels in BOS [35], suggesting that fibrocytes can modulate the microenvironment during or following hypoxia. Initial recruitment may result in increased permeability of the bronchial/pulmonary circulations, whereas chronic recruitment will ultimately lead to altered composition of the extracellular matrix (ECM), as well as induction of damage-associated molecular patterns (DAMPs). DAMPs are specifically generated upon tissue injury and activate receptors detecting danger signals, such as RAGE (receptor for advanced glycation end products) and Toll-like receptors. These receptors are also activated by a number of molecules, such as versican, biglycan and fragments of hyaluronan and heparan sulphate [36], and thus represent a key link between infection, tissue injury and ultimately repair. Importantly, these ECM molecules are also involved in activation of the CXCR4/CXCL12 axis as well as binding of both transforming growth factor (TGF)- $\beta$ and VEGF [35].

The article by MARTIN et al. [4] in this issue of the ERJ highlights the importance of and the need to obtain more knowledge about the link between angiogenesis and pathogen-associated airway infection. The available literature indicates that it may be of importance to consider the role of DAMPs together with hypoxia in this interplay. Such research may have broad significance in a variety of airway diseases and potentially have modern therapeutic implications for pathophysiologies first described in 19th century translational European research.

\section{STATEMENT OF INTEREST}

None declared.

\section{REFERENCES}

1 O'Donnell AE. Bronchiectasis. Chest 2008; 134: 815-823.

2 Pasteur MC, Bilton D, Hill AT. British Thoracic Society guideline for non-CF bronchiectasis. Thorax 2010; 65: Suppl. 1, i1-i58.

3 Laennec RTH. De l'Auscultation Mediate ou Traite du Diagnostic des Madadies des Poumons et du Coeur. [On Mediate Auscultation or Treatise on the Diagnosis of the Diseases of the Lungs and Heart.] Paris, Brosson and Chaudé, 1819.

4 Martin C, Thévenot G, Danel S, et al. Pseudomonas aeruginosa induces vascular endothelial growth factor synthesis in airway epithelium in vitro and in vivo. Eur Respir J 2011; 38: 939-946.

5 Song JW, Im JG, Shim YS, et al. Hypertrophied bronchial artery at thin-section CT in patients with bronchiectasis: correlation with CT angiographic findings. Radiology 1998; 208: 187-191.

6 Yoo DH, Yoon CJ, Kang SG, et al. Bronchial and nonbronchial systemic artery embolization in patients with major hemoptysis: safety and efficacy of N-butyl cyanoacrylate. AJR Am J Roentgenol 2011; 196: W199-W204.

7 McDonald DM. Angiogenesis and remodeling of airway vasculature in chronic inflammation. Am J Respir Crit Care Med 2001; 164: S39-S45.

8 Morrissey BM, Evans SJ. Severe bronchiectasis. Clin Rev Allergy Immunol 2003; 25: 233-247. 
9 Khor YH, Teoh AK, Lam SM, et al. Increased vascular permeability precedes cellular inflammation as asthma control deteriorates. Clin Exp Allergy 2009; 39: 1659-1667.

10 Hoshino M, Nakamura Y, Hamid QA. Gene expression of vascular endothelial growth factor and its receptors and angiogenesis in bronchial asthma. J Allergy Clin Immunol 2001; 107: 1034-1038.

11 Orsida BE, Li X, Hickey B, et al. Vascularity in asthmatic airways: relation to inhaled steroid dose. Thorax 1999; 54: 289-295.

12 Walters EH, Reid D, Soltani A, et al. Angiogenesis: a potentially critical part of remodelling in chronic airway diseases? Pharmacol Ther 2008; 118: 128-137.

13 Feltis BN, Wignarajah D, Zheng L, et al. Increased vascular endothelial growth factor and receptors: relationship to angiogenesis in asthma. Am J Respir Crit Care Med 2006; 173: 1201-1207.

14 Langenbach SY, Zheng L, McWilliams T, et al. Airway vascular changes after lung transplant: potential contribution to the pathophysiology of bronchiolitis obliterans syndrome. J Heart Lung Transplant 2005; 24: 1550-1556.

15 Zheng L, Orsida BE, Ward C, et al. Airway vascular changes in lung allograft recipients. J Heart Lung Transplant 1999; 18: 231-238.

16 Anderson RL, Hiemstra PS, Ward C, et al. Antimicrobial peptides in lung transplant recipients with bronchiolitis obliterans syndrome. Eur Respir J 2008; 32: 670-677.

17 Koczulla R, von Degenfeld G, Kupatt C, et al. An angiogenic role for the human peptide antibiotic LL-37/hCAP-18. J Clin Invest 2003; 111: 1665-1672.

18 Gibson PG, Simpson JL. The overlap syndrome of asthma and COPD: what are its features and how important is it? Thorax 2009; 64: 728-735.

19 Kasahara Y, Tuder RM, Cool CD, et al. Endothelial cell death and decreased expression of vascular endothelial growth factor and vascular endothelial growth factor receptor 2 in emphysema. Am J Respir Crit Care Med 2001; 163: 737-744.

20 Calabrese C, Bocchino V, Vatrella A, et al. Evidence of angiogenesis in bronchial biopsies of smokers with and without airway obstruction. Respir Med 2006; 100: 1415-1422.

21 Hiroshima K, Iyoda A, Shibuya K, et al. Evidence of neoangiogenesis and an increase in the number of proliferating cells within the bronchial epithelium of smokers. Cancer 2002; 95: 1539-1545.

22 Kranenburg AR, de Boer WI, Alagappan VK, et al. Enhanced bronchial expression of vascular endothelial growth factor and receptors (Flk-1 and Flt-1) in patients with chronic obstructive pulmonary disease. Thorax 2005; 60: 106-113.

23 Kanazawa H, Asai K, Hirata K, et al. Possible effects of vascular endothelial growth factor in the pathogenesis of chronic obstructive pulmonary disease. Am J Med 2003; 114: 354-358.

24 Soltani A, Reid DW, Sohal SS, et al. Basement membrane and vascular remodelling in smokers and chronic obstructive pulmonary disease: a cross-sectional study. Respir Res 2010; 11: 105.

25 Bhattacharya J. Lung neovascularization: a tale of two circulations. Am J Physiol Lung Cell Mol Physiol 2008; 294: L417-L418.

26 Rydell-Tormanen K, Uller L, Erjefalt JS. Remodeling of extra-bronchial lung vasculature following allergic airway inflammation. Respir Res 2008; 9: 18.

27 Rydell-Tormanen K, Johnson JR, Fattouh R, et al. Induction of vascular remodeling in the lung by chronic house dust mite exposure. Am J Respir Cell Mol Biol 2008; 39: 61-67.

28 Rydell-Tormanen K, Uller L, Erjefalt JS. Allergic airway inflammation initiates long-term vascular remodeling of the pulmonary circulation. Int Arch Allergy Immunol 2009; 149: 251-258.

29 Daley E, Emson C, Guignabert C, et al. Pulmonary arterial remodeling induced by a Th2 immune response. J Exp Med 2008; 205: 361-372.

30 Witzenrath M, Ahrens B, Kube SM, et al. Allergic lung inflammation induces pulmonary vascular hyperresponsiveness. Eur Respir J 2006; 28: 370-377.

31 Signorelli S, Jennings P, Leonard MO, et al. Differential effects of hypoxic stress in alveolar epithelial cells and microvascular endothelial cells. Cell Physiol Biochem 2009; 25: 135-144.

32 Gardner LB, Corn PG. Hypoxic regulation of mRNA expression. Cell Cycle 2008; 7: 1916-1924.

33 Ceradini DJ, Gurtner GC. Homing to hypoxia: HIF-1 as a mediator of progenitor cell recruitment to injured tissue. Trends Cardiovasc Med 2005; 15: 57-63.

34 Kucia M, Jankowski K, Reca R, et al. CXCR4-SDF-1 signalling, locomotion, chemotaxis and adhesion. J Mol Histol 2004; 35: 233-245.

35 Andersson-Sjoland A, Erjefalt JS, Bjermer L, et al. Fibrocytes are associated with vascular and parenchymal remodelling in patients with obliterative bronchiolitis. Respir Res 2009; 10: 103.

36 Piccinini AM, Midwood KS. DAMPening inflammation by modulating TLR signalling. Mediators Inflamm 2010; 2010: 672395. 